\title{
A Preliminary Investigation: Alvimopan Use to Prevent Post-Operative Ileus after Radical Cystectomy with Urinary Diversion
}

\author{
Benjamin F. Katz ${ }^{1 *}$, Geoffrey S. Gaunay ${ }^{1}$, Basir U. Tareen ${ }^{2}$, Erik T. Goluboff ${ }^{1}$ \\ ${ }^{1}$ Department of Urology, Beth Israel Medical Center, New York, USA \\ ${ }^{2}$ Department of Urology, Metropolitan Urologic Associates, Woodbury, USA \\ Email: "bkatz@chpnet.org
}

Received July 30, 2013; revised August 28, 2013; accepted September 5, 2013

Copyright (C) 2013 Benjamin F. Katz et al. This is an open access article distributed under the Creative Commons Attribution License, which permits unrestricted use, distribution, and reproduction in any medium, provided the original work is properly cited.

\begin{abstract}
Background: Postoperative ileus (POI) is a common and frustrating patient complication after a urinary diversion by using a segment of bowel. Alvimopan is an oral selective antagonist to the peripheral $\mu$-opioid receptor. Our study investigates the effect of alvimopan on POI in patients undergoing radical cystectomy. There are no documented studies on alvimopan's efficacy in urologic surgery literature. Methods: Approval from the Institutional Review Board was obtained to conduct a retrospective review of patients' records from August 2009 until August 2011. The study included sixteen patients who had undergone radical cystectomy with ileal diversion. Exclusion criteria included patients with chronic opioid use, previous colostomy or ileostomy, or significant comorbidities which could cause increased postoperative complications. Statistical analysis was performed to examine the association of alvimopan use with decreased time to dietary advancement and decreased length of hospital stay. Results: The alvimopan group advanced their diet more than 24 hours earlier in comparison with the alvimopan naïve group $(\mathrm{P}<0.0433)$, and the alvimopan group had a greater had a greater or $26 \%$ shorter hospital length $(\mathrm{P}<0.0451)$ than one day. We showed a reduced risk of POI and subsequent decreased hospital course length. There was no significant difference in readmission rate or need for nasogastric tube (NGT). Interpretation: To our knowledge we report one of the first uses of alvimopan in reducing POI in the urological surgery literature. Our novel experience with using this drug is encouraging. Further research will ultimately determine if standard use of alvimopan to decrease POI in radical cystectomy with ileal diversion will be implemented.
\end{abstract}

Keywords: Cystectomy; Urinary Diversion; Alvimopan; Ileus

\section{Introduction}

In 2009 , there were over 70,000 new diagnoses of bladder cancer and more than 14,000 deaths, making bladder cancer the $5^{\text {th }}$ most common malignancy in the United States [1]. Although chemotherapy and radiation therapy are options for select patients, the gold standard for muscle invasive disease continues to be radical cystectomy with urinary diversion. Reconstruction of the urinary tract is a necessity in order to preserve renal function. There are numerous diversions and reconstructions described in the literature and most require the use of small or large bowel.

*Corresponding author.
Radical cystectomy continues to be a morbid procedure fraught with complications. Ileus is a common occurrence leading to patient discomfort and increased length of hospital stay [2]. Post-operative ileus (POI) is defined as a "transient impairment of bowel motility" [3]. This condition may lead to nausea, vomiting, prolonged hospital stay, bowel distention, abdominal pain, and, in severe cases, aspiration [3,4]. POI may also lead to readmission and more expensive hospital stays costing over \$4000 (\$4118 - \$8785) [5]. The overall healthcare costs from POI in the United States are estimated to be over $\$ 1.46$ billion annually [5].

It has been hypothesized that POI is caused by both an inflammatory as well as a neural process. However, the 
process is multifactorial. The inflammatory response is believed to be directly related to surgical injury of the viscera triggering an immunologic response, and the complex neural process involves the somatic, adrenergic, and endogenous stress mediated pathways [6]. Opioid use has been shown to exacerbate POI. The peripheral $\mu$-opioid receptor on the gastrointestinal tract has been found to be a main contributory factor to POI when the receptor is activated. By using opioid for post-surgical pain control, the $\mu$-receptor activation can lead to increased colonic muscle tone and decreased peristalsis in the GI tract [7].

Alvimopan is an oral selective antagonist to the peripheral $\mu$-opioid receptor. Due to alvimopan's large size, zwitterionic form, and polarity, alvimopan does not cross the blood-brain barrier, therefore allowing opioid central analgesia [8]. Alvimopan has been shown to lower the incidence of nasogastric tube insertion postoperatively, and decrease POI and subsequently decrease hospital stay by approximately one day $[8,9]$. The efficacy and safety of the $12 \mathrm{mg}$ oral dose has been well described in the gastrointestinal and gynecologic surgery literature.

In the present study, our aim was to investigate the effect of alvimopan on POI in patients undergoing radical cystectomy. Tolerance of a clear liquid diet and hospital length of stay were used as surrogate markers for bowel function. There are no documented studies on alvimopan's efficacy in urologic surgeries.

\section{Material and Methods}

Approval from the Institutional Review Board was obtained to conduct a retrospective review of patients' records from August 2009 until August 2011. The study included sixteen patients who had undergone radical cystectomy with ileal diversion. Exclusion criteria included patients with chronic opioid use, previous colostomy or ileostomy, or significant comorbidities which could cause increased postoperative complications. The 16 patients were consecutive cases performed by two different surgeons in one institution; no patients were excluded in the trial.

All patients had their complete hospital medical records and preoperative evaluation reviewed. Patients' demographics included age, sex, race, BMI, procedure, morbidities, need for nasogastric tube, days until clear liquids, length of stay, surgeon and use of alvimopan were evaluated. For the purpose of this study, morbidities were defined as any inpatient serious adverse events or readmission within 30 days postoperatively.

The cystectomy postoperative pathway in our patients includes pain management, encouragement of early ambulation, incentive spirometry and advancing the patient to a clear liquid diet once flatus is reported. Patients were separated into two arms; alvimopan $12 \mathrm{mg}$ and alvimo- pan naïve. The alvimopan arm was given $12 \mathrm{mg}$ orally 1 to 2 hours preoperatively in the preoperative holding area and continued on alvimopan $12 \mathrm{mg}$ twice daily until discharge.

Statistical analysis was performed to examine the association of alvimopan use with decreased time to dietary advancement and decreased length of hospital stay. Univariante analysis was obtained with $\mathrm{P}<0.05$. All statistical tests were achieved using Stata (College Station, TX), version 12 .

\section{Results}

Sixteen consecutive patients were identified during the allocated time period and all 16 patients were included in our study. Of the 16 patients, 8 received alvimopan and 8 were alvimopan naïve. Mean patient age was 63.5 (range 46 to 78 ) and mean body mass index was $26 \mathrm{~kg} / \mathrm{m}^{2}$ (range 17 to 37$)$. There were 4 females (25\%) and all cases were radical cystectomy with ileal noncontinent conduit. The majority of the patients were Caucasian $(56 \%)$, followed by Asian (19\%) and Hispanic (19\%).

According to Table 1, the naïve arm was younger and had a lower BMI as compared to the alvimopan group, which had five patients over the age of 65 compared to just one in the naïve group. The race and gender of the two groups were similar. The alvimopan patients had significantly less POI as compared to the alvimopan naive arm. Statistical significance was achieved with a $\mathrm{P}$ value 0.0433 when comparing the two arms for advancement to a clear liquid diet. The median time to a clear liquid diet was 3 days versus 4.1 days in the alvimopan group versus the naïve group, respectively. The hospital course was shorter as well, with the alvimopan group going home in a mean of 5.1 days versus 6.9 days

Table 1. Baseline patient demographics.

\begin{tabular}{ccc}
\hline Demographics & Naïve (n= 8) & Alvimopan (n = 8) \\
\hline Age (y) & $60.4 \pm 7.8$ & $66.6 \pm 10.1$ \\
Mean \pm SD & $1(13 \%)$ & $5(63 \%)$ \\
$\geq 65, \mathrm{n}(\%)$ & & \\
Race, n (\%) & $5(63 \%)$ & $4(50 \%)$ \\
Caucasian & $1(13 \%)$ & $2(25 \%)$ \\
Asian & $2(25 \%)$ & $1(13 \%)$ \\
Hispanic & 0 & $1(13 \%)$ \\
African American & & $2(25 \%)$ \\
Gender, n (\%) & $2(25 \%)$ & \\
Female & & $27.8 \pm 3.6$ \\
BMI & $1(13 \%)$ & $25 \%)$ \\
Mean \pm SD & & \\
$\geq 30, n(\%)$ & & \\
\hline
\end{tabular}

*BMI, body mass index; calculated as $\mathrm{kg} / \mathrm{m}^{2}$. 
in the naïve group (Table 2). This variable also reached statistical significance with a $\mathrm{P}$ value of 0.0451 .

The readmission rate also favored the alvimopan group, with two patients being readmitted for an infection and bleeding duodenal ulcer (Clavien Classification II and I respectively). The control group had four out of eight patients readmitted within 30 days for 2 fevers and 2 abscess formation requiring intervention (Clavien Classification II and III respectively). It was expected that the naïve group would have less complications due to their younger age and lower BMI. None of the patients in either group were readmitted for POI, small bowel obstruction or failure to thrive. Nasogastric tube insertion was zero in both arms of the study.

\section{Discussion}

Post-operative ileus is a very expensive and frustrating condition that affects many post-surgical patients. No research on the use of alvimopan in preventing POI has been reported in the urologic literature. This initial study is the first report of alvimopan use in urologic surgery. By starting $12 \mathrm{mg}$ alvimopan prior to surgery and subsequently prior to opioid use, our goal was to block the $\mu$-opioid receptors and diminish POI. Statistical significance was achieved in our limited sample size for both key factors in POI. The alvimopan group advanced their diet more than 24 hours earlier in comparison to the alvimopan naïve group, and the alvimopan group had a greater than one day or $26 \%$ shorter hospital length. We showed a reduced risk of POI and subsequent decreased hospital course length.

According to Bell and colleagues, a hospital day costs an estimated $\$ 1300$ to $\$ 1600$ a day for a bowel resection procedure. The $\$ 62.50$ per dose of alvimopan if extrapolated out to a five day hospital course would be equivalent to around ten doses [5]. This cost, although not insignificant, pales in comparison to one or more days in the hospital. The Bell study goes on to state that the total hospital savings was averaged to " $\$ 977$ less for patients who received alvimopan [5]. Our study had a greater

Table 2. Alvimopan versus control outcomes.

\begin{tabular}{cccc}
\hline & Naïve $(\mathbf{n}=8)$ & Alvimopan $(\mathbf{n}=8)$ & P Value \\
\hline $\begin{array}{c}\text { Days until PO order } \\
\text { Mean } \pm \text { SD } \\
\text { NGT placed, } \mathrm{n}\end{array}$ & $4.1 \pm 1.5$ & $3 \pm 0.9$ & 0.0433 \\
Hospital Length Days \\
Mean \pm SD
\end{tabular}

than one and half day shorter hospital course and a much sooner time to bowel recovery.

The use of alvimopan has been described in the general surgery and gynecology literature for the prevention of ileus [4,10]. According to Herzog et al., a double-blind placebo controlled randomized trial using alvimopan in female patients undergoing total abdominal hysterectomy which did not resect bowel resulted in first bowel movement 22 hours earlier and a safety profile similar to placebo [4]. Our patients did not report any allergies or adverse reactions; however, our study design was not specifically designed to look at such results.

The naïve group had an estimated four days until the patient's diet was advanced on the report of flatus. Multiple other novel concepts have been reported to hasten bowel recovery time. Erythromycin and early removal of a nasogastric tube was not shown to improve time to bowel sounds, flatus, passage of first bowel movement or prevention of ileus $[11,12]$. Pruthi and colleagues described a perioperative care plan involving, but not limited to, restricting bowel preparation, reducing incisional length, and limiting narcotic analgesics. The study showed a significant improvement from 1996-1997 of mean time to clear liquid diet starting at 6.9 baseline and improving to 2.0 days in the 2001-2002 current pathway [13]. Perhaps the easiest and least expensive attempt to shorten POI has been shown in gum chewing studies. Kouba study and Choi study both found gum chewing to improve time to flatus by 0.5 days $[13,14]$. Our study found time to flatus and advancement of diet by more than a day, and unlike the Kouba study, we found a significant decrease in hospital length of stay. Choi did not report data on length of hospital stay.

The alvimopan group had a slightly higher BMI and age as compared to the controls. Increasing BMI and age are "independent risk factors for the development of postoperative paralytic ileus after radical cystectomy" according to Svatek et al. [15]. They report POI in $10 \%$ of "normal" weight patients (BMI $18.5-24.9 \mathrm{~kg} / \mathrm{m}^{2}$ ) and POI in $22.2 \%$ and $30.3 \%$ in BMI $30-34.9 \mathrm{~kg} / \mathrm{m}^{2}$ and $\geq 35 \mathrm{~kg} / \mathrm{m}^{2}$ respectively. Svatek et al. did not show a difference in POI when comparing EBL, need for blood transfusion, operative time, the type of urinary diversion, or use of epidural anesthesia [15]. Our alvimopan group had a higher BMI (27.8 vs 24.9) and a higher age cohort (66.6 vs. 60.4) as compared with the controls. One would postulate that the alvimopan group should have a higher rate of POI, but this was not the case. Statistical significance was still obtained in our experimental arm.

This is one of the first reports of the use of alvimopan in the urologic surgery literature to date to our knowledge. There are limitations to this study. The limited sample size poses a selection and sample bias. We were able to show statistical significance; however, to deter- 
mine the true impact of the results, the study should be conducted on a much larger scale. The retrospective, nonrandomized, single institution design implores us to study this drug further. This initial report was intended to show a preliminary trend towards decreasing the morbidity of POI in radical cystectomy with ileal diversion by using the drug alvimopan. Further and more detailed research is evidently needed to decipher objectively the use of alvimopan in urologic procedures.

\section{Conclusion}

To our knowledge we report one of the first uses of alvimopan in reducing POI in the urological surgery literature. Our novel experience with using this drug is encouraging. Further research will ultimately determine if standard use of alvimopan to decrease POI in radical cystectomy with ileal diversion will be implemented.

\section{REFERENCES}

[1] A. Jemal, R. Siegel, E. Ward, Y. Hao, J. Xu and M. J. Thun, "Cancer Statistics, 2009," CA: A Cancer Journal for Clinicians, Vol. 59, No. 4, 2009, pp. 225-249. http://dx.doi.org/10.3322/caac.20006

[2] M. Maffezzini, F. Campodonico, G. Canepa, et al., "Current Perioperative Management of Radical Cystectomy with Intestinal Urinary Reconstruction for Muscle-Invasive Bladder Cancer and Reduction of the Incidence of Postoperative Ileus," Surgical Oncology, Vol. 17, No. 1, 2008, pp. 41-48. http://dx.doi.org/10.1016/j.suronc.2007.09.003

[3] E. K. Tan, J. Cornish, A. W. Darzi and P. P. Tekkis, "Meta-Analysis: Alvimopan vs. Placebo in the Treatment of Post-operative Ileus," Alimentary Pharmacology \& Therapeutics, Vol. 25, No. 1, 2006, pp. 47-57.

[4] T. Herzog, R. Coleman, J. Guerrieri, et al., "A Doubleblind, Randomized, Placebo-Controlled Phase III Study of the Safety of Alvimopan in Patients Who Undergo Simple Total Abdominal Hysterectomy," American Journal of Obstetrics \& Gynecology, Vol. 195, No. 2, 2006, pp. 445-453. http://dx.doi.org/10.1016/j.ajog.2006.01.039

[5] T. Bell, S. Poston, M. Kraft, et al., "Economic Analysis of Alvimopan in North American Phase III Efficacy Trials," American Journal of Health-System Pharmacy, Vol. 66, No. 15, 2009, pp. 1362-1368. http://dx.doi.org/10.2146/ajhp080329
[6] J. Schmidt, B. Stoffels, A. Nazir, et al., "Alvimopan and COX-2 Inhibition Reverse Opioid and Inflammatory Components for Postoperative Ileus," Neurogastroenterology \& Motility, Vol. 20, No. 6, 2008, pp. 689-699. http://dx.doi.org/10.1111/j.1365-2982.2007.01078.x

[7] C. Delaney, U. Yasothan and P. Kirkpartrick, "Alvimopan," Nature Reviews: Drug Discovery, Vol. 7, No. , 2008, pp. 727-728. http://dx.doi.org/10.1038/nrd2668

[8] H. Bream-Rouwenhorst and M. Cantrell, "Alvimopan for Postoperative Ileus," American Journal of Health-System Pharmacy, Vol. 66, No. 14, 2009, pp. 1267-1277. http://dx.doi.org/10.2146/ajhp080445

[9] B. Wolff, J. Weese, K. Ludwig, et al., "Postoperative Ileus-Related Morbidity Profile in Patients Treated with Alvimopan after Bowel Resection," Journal of the American College of Surgeons, Vol. 204, No. 4, 2007, pp. 609616. http://dx.doi.org/10.1016/j.jamcollsurg.2007.01.041

[10] I. Obokhare, B. Champagne, S. Stein, et al., "The Effect of Alvimopan on Recovery after Laparoscopic Segmental Colectomy," Diseases of the Colon \& Rectum, Vol. 54, No. 6, 2011, pp. 743-746. http://dx.doi.org/10.1007/DCR.0b013e318217ed17

[11] A. Lightfoot, M. Eno, K. Kreder, et al., "Treatment of Postoperative Ileus after Bowel Surgery with Low-Dose Intravenous Erythromycin," Journal of Urology, 2007, Vol. 69, No. 4, 2007, pp. 611-615. http://dx.doi.org/10.1016/j.urology.2006.12.027

[12] H. Park, C. Kwak, S. Byun, et al., "Early Removal of Nasogastric Tube after Cystectomy with Urinary Diversion: Does Postoperative Ileus Risk Increase?" Journal of Urology, Vol. 65, No. 5, 2004, pp. 905-908.

[13] E. Kouba, E. Wallen and S. Pruthi, "Gum Chewing Stimulates Bowel Motility in Patients Undergiong Radical Cystec-Tomy with Urinary Diversion," Journal of Urology, Vol. 70, No. 6, 2007, pp. 1053-1056. http://dx.doi.org/10.1016/j.urology.2007.07.048

[14] H. Choi, S. Kang, D. Yoon, et al., "Chewing Gum Has a Stimulatory Effect on Bowel Motility in Patients after Open or Robotic Radical Cystectomy for Bladder Cancer: A Prosperctive Randomized Comparative Study," Journal of Urology, Vol. 77, No. 4, 2011, pp. 884-890. http://dx.doi.org/10.1016/j.urology.2010.06.042

[15] R. Svatek, M. Fisher, M. Williams, et al., "Age and Body Mass Index Are Independent Risk Factors for the Development of Postoperative Paralytic Ileus after Radical Cystectomy," Journal of Urology, Vol. 76, No. 6, 2010, pp. 1419-1424. 